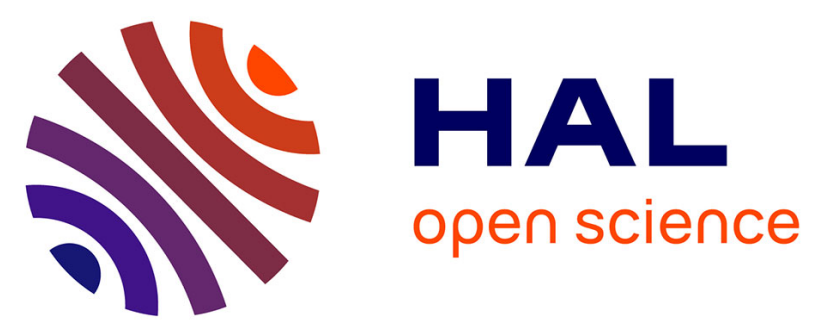

\title{
Crystallization pathway from highly viscous colloidal suspension to ultra-small FAU zeolite nanocrystals
}

Hussein Awala, Shrikant M Kunjir, Aurélie Vicente, Jean-Pierre Gilson,

Valentin Valtchev, Hussein Seblani, Richard Retoux, Louwanda Lakiss, Christian Fernandez, Robert Bedard, et al.

\section{To cite this version:}

Hussein Awala, Shrikant M Kunjir, Aurélie Vicente, Jean-Pierre Gilson, Valentin Valtchev, et al.. Crystallization pathway from highly viscous colloidal suspension to ultra-small FAU zeolite nanocrystals. Journal of Materials Chemistry A, 2021, 9 (32), pp.17492-17501. 10.1039/D1TA02781F . hal03414922

\section{HAL Id: hal-03414922 \\ https://hal.science/hal-03414922}

Submitted on 4 Nov 2021

HAL is a multi-disciplinary open access archive for the deposit and dissemination of scientific research documents, whether they are published or not. The documents may come from teaching and research institutions in France or abroad, or from public or private research centers.
L'archive ouverte pluridisciplinaire $\mathbf{H A L}$, est destinée au dépôt et à la diffusion de documents scientifiques de niveau recherche, publiés ou non, émanant des établissements d'enseignement et de recherche français ou étrangers, des laboratoires publics ou privés. 


\title{
Crystallization pathway from highly viscous colloidal suspension to ultra-small FAU zeolite nanocrystals
}

Hussein Awala, ${ }^{1}$ Shrikant M. Kunjir, ${ }^{1}$ Aurélie Vicente, ${ }^{1}$ Jean-Pierre Gilson, ${ }^{1}$ Valentin Valtchev, ${ }^{1}$ Hussein Seblani, ${ }^{1}$ Richard Retoux, ${ }^{2}$ Louwanda Lakiss, ${ }^{1}$ Christian Fernandez, ${ }^{1}$ Robert Bedard, ${ }^{3}$ Suheil Abdo, ${ }^{3}$ Jeffery Bricker, ${ }^{3}$ Svetlana Mintova ${ }^{1 *}$

${ }^{1}$ Normandie Université, ENSICAEN, UNICAEN, CNRS, LCS, 14000 Caen, France

${ }^{2}$ Normandie Université, ENSICAEN, UNICAEN, CNRS, CRISMAT, 14000 Caen, France

${ }^{3}$ UOP-Honeywell LLC, R\&D, 25 East Algonquin Road, Des Plaines, IL 60016, USA

\begin{abstract}
The crystallization kinetics of template free ultra-small FAU-type zeolite $(\mathrm{X})$ in highly alkaline viscous precursor suspensions is investigated. We focus on understanding the crystallization pathway from a viscous amorphous precursor suspension into nanosized FAU crystals with high phase purity and yield. The crystallization develops in a four-step process: (1) preparation of a clear and stable precursor suspension by a controlled mixing of silica and alumina colloidal suspensions at low temperature $\left(4{ }^{\circ} \mathrm{C}\right)$, (2) aging the colloidal suspension at room temperature, (3) partial evaporation of water of the colloidal suspension to produce a highly viscous suspension with an amorphous nanoparticles with a monomodal particle size distribution, (4) hydrothermal treatment at low temperature $\left(50{ }^{\circ} \mathrm{C}\right)$ to transform the amorphous nanoparticles into FAU type nanocrystals with the same particle size while preventing agglomeration and sedimentation. The properties (size and morphology) of the amorphous particles depend on the mixing procedure (temperature and speed of mixing) and alkalinity of the colloidal suspension. The high alkalinity of the suspension leads to the formation of ultra-small discrete nanoparticles with a monomodal particle size distribution. During the aging step (2), secondary building units characteristic of the FAU framework structure are detected (Raman and IR spectroscopy) in the amorphous aluminosilicate particles. During the evaporation of water of the colloidal suspension (3), prior to hydrothermal synthesis, double-six membered rings (D6R), the secondary building units of the FAU structure were detected by in$s i t u{ }^{29} \mathrm{Si}$ NMR spectroscopy. Formation of the very first micropores in the nanosized particles was further confirmed by $\mathrm{HP}^{129} \mathrm{Xe}$ NMR spectroscopic measurements.
\end{abstract}

\section{Introduction}

Zeolites are crystalline aluminosilicates with unique properties easily tuneable by engineering their chemical composition, topologies, morphologies, acidity, thermal stability, extra framework cations and porosity. The commercial relevance of zeolites has been demonstrated by a wide range of applications in oil refining, petrochemistry, fine chemicals, gas and liquid separations and purification, photonics, and drug delivery. ${ }^{[1-7]}$ Up to now, more than 253 different framework types have been synthesized, ${ }^{[8]}$ mostly in the presence of organic structure directing agents (OSDA) which enhance kinetic rates and orient the selectivity of zeolite crystallization by stabilizing metastable structures in a wide range of chemical composition. ${ }^{[9-13]}$ It is noteworthy that only a few nanosized zeolites have been synthesized without 
OSDA $^{[14-22]}$ which highlights our current inability to use the fundamental understanding of zeolite crystal growth to design zeolites with specific properties, one of the most important challenge in zeolite synthesis. Recently, we published novel OSDA-free synthesis routes for nanosized EMT-, FAU-, SOD-, RHO- and CHA- type zeolites. ${ }^{[23-26]}$ However, despite the good progress made in the synthesis of nanosized OSDAfree zeolites, many mechanistic issues remain to be addressed to optimize the syntheses and prepare novel zeolites with nanosized dimensions. When conducting synthesis work to address these issues, key parameters to be considered begin with the selection of the initial sources for silica, alumina and alkali cations (their hydrated form being the templates), followed by establishing the best conditions for the preparation of the initial precursors. For example, silicate species formed during the dissolution of the silica source play an important role in the zeolite formation and its particle size distribution and morphology. ${ }^{[27]}$ In addition, the formation of the initial gel with particle sizes less than $10 \mathrm{~nm}$ from monomeric and low molecular weight aluminosilicate species ensuring a fast exchange between the solid and liquid phases is an important step not yet fully understood. Another important parameter is a low temperature $\left(<60{ }^{\circ} \mathrm{C}\right)$ hydrothermal synthesis, minimizing Ostwald ripening, during crystallization preserving the small size of the parent amorphous particles. ${ }^{[28]}$

Enormous effort has been dedicated to understand the zeolite growth process in hydrogels under hydrothermal conditions to harvest zeolite crystals with desired properties. ${ }^{[29,30]}$ The main challenge in zeolite synthesis is the incomplete understanding of the molecular-level interactions, the kinetic and thermodynamic driving forces governing the interactions and binding of templates (organic or inorganic) to precursors leading to specific nucleation and crystallization events. Still the open questions is what happens at the earliest stages of nucleation -where \& when are the first organized «crystals » are produced. The formation of a particular zeolite could occur by more than one crystallization pathway as described. ${ }^{[28,31]}$ An additional motivation for the current work is that the preparation of nanosized zeolites from OSDA-free clear precursor suspensions is highly desired from a cost and environmental perspective, especially when the synthesis takes place at moderate and low temperatures $\left(30-130{ }^{\circ} \mathrm{C}\right) .{ }^{[32]}$ For this reason, many attempts to reduce temperature and OSDA consumption have already been published ${ }^{[28]}$ as well as the crystallization kinetics of several OSDA-free nanozeolites. ${ }^{[33]}$ However, to improve our understanding ability to control these synthesis processes, the formation of the very first secondary building units in the nanosized amorphous particles needs further attention to better understand the selective formation of specific zeolites. In this work, we focus on the synthesis of ultra-small FAU nanosized zeolite from highly reactive and costeffective $\mathrm{Si}$ and $\mathrm{Al}$ sources with a high colloidal stability which might be usable in larger scale production of nanosized FAU type zeolites. We then facilitate this synthesis by first preparing and stabilizing clear precursor suspensions containing well-defined, discrete amorphous particles. The size, phase purity and chemical composition of the derived FAU crystals are then controlled by adjusting the composition of this precursor suspension, with a particular focus on the water amount in the aging and de-hydration steps. Results of our effort to track the crystallization pathway from highly concentrated clear and viscous suspension to ultra-small FAU nanosized crystals by advanced microscopic and spectroscopic techniques and the insight gained into the crystallization pathways and the specific characteristics of the synthesized nanosized zeolite will be presented. 


\section{Experimental Section}

\subsection{Materials and Zeolite Synthesis.}

The following starting chemicals are used as such: Ludox HS-30 (Aldrich, $30 \% \mathrm{SiO}_{2}$, particle size of 3-4 $\mathrm{nm}$, stabilized with sodium hydroxide, $\mathrm{pH}$ of 9.3), sodium aluminate (Sigma-Aldrich, anhydrous, 50-56\% $\mathrm{Al}_{2} \mathrm{O}_{3} ; 40-45 \% \mathrm{Na}_{2} \mathrm{O} ; \leq 0.05 \% \mathrm{Fe}$ ) and sodium hydroxide ( $\mathrm{NaOH}$, Prolabo, $98.7 \%$ ).

This four-step process is illustrated in Figure 1:

- Step 1: preparation of two solutions: Solution A (sodium aluminate) by dissolving sodium aluminate $(1.02 \mathrm{~g})$ in $3 \mathrm{~g}$ of double distilled (dd) water and Solution B (sodium silicates) by mixing $10 \mathrm{~g}$ of colloidal silica (Ludox HS-30) with $3.25 \mathrm{~g}$ of sodium hydroxide ( $\mathrm{NaOH}$, Prolabo, 98.7\%) and $0.98 \mathrm{~g}$ of $\mathrm{dd}_{2} \mathrm{O}$ in a closed PP bottle (process is highly exothermic). A turbid suspension first appears and evolves as a water clear suspension within two minutes. The formation of amorphous particles from both solutions $\mathrm{A}$ and $\mathrm{B}$, providing monomeric or low molecular weight species upon mixing with sodium hydroxide is monitored by DLS (Figure S1). Solution A is then added dropwise to solution B under vigorously stirring maintained at low temperature in an ice-bath. The resulting precursor suspension has the chemical composition: $8.5 \mathrm{Na}_{2} \mathrm{O}: 1.1 \mathrm{Al}_{2} \mathrm{O}_{3}: 10 \mathrm{SiO}_{2}: 122$ $\mathrm{H}_{2} \mathrm{O}$.

- Step 2: The step 1 suspension is kept for $24 \mathrm{~h}$ at room temperature for aging.

- Step 3: Partial evaporation of water under vacuum. The resulting composition of the precursor suspension is: $8.5 \mathrm{Na}_{2} \mathrm{O}: 1.1 \mathrm{Al}_{2} \mathrm{O}_{3}: 10 \mathrm{SiO}_{2}: 50 \mathrm{H}_{2} \mathrm{O}$.

- Step 4: Hydrothermal treatment of the viscous step 3 suspension at $50^{\circ} \mathrm{C}$ from $45 \mathrm{~min}$ to $24 \mathrm{~h}$.

The precursor suspensions from steps 1, 2, and 3 are labeled P-1, P-2, and P-3, respectively. The solids harvested after the hydrothermal treatments in step 4 for $45 \mathrm{~min}, 3 \mathrm{~h}$ and $24 \mathrm{~h}$ are referred as FAU- 45 min, FAU-3 h and FAU-24 h, respectively. The solid products were purified by double distilled water till $\mathrm{pH}=7.5$, separated using high-speed centrifuge and freeze dried to prevent the agglomeration of the particles prior further characterizations. 


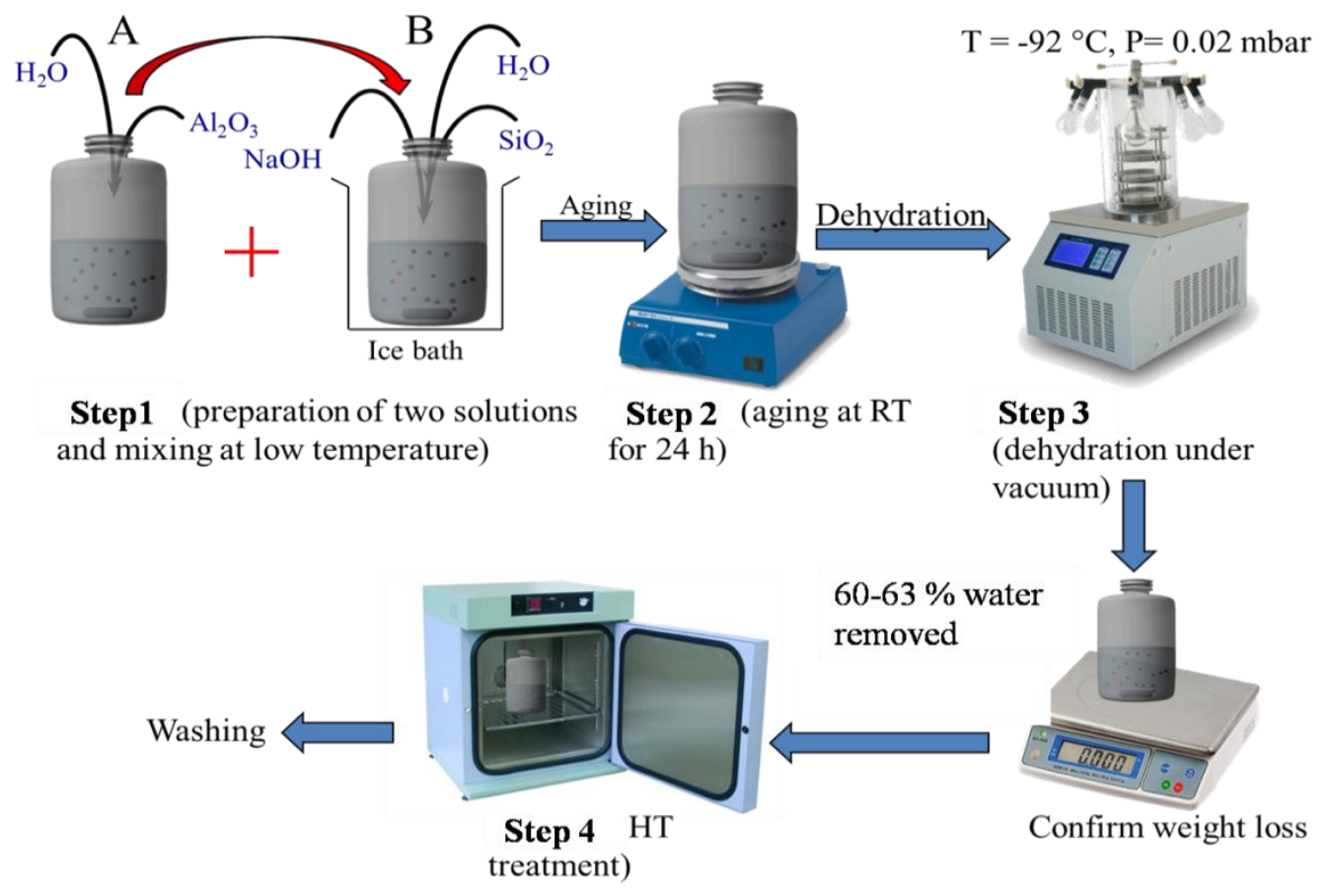

Figure 1. Schematic representation of the preparation of ultra-small FAU-X nanosized zeolite: Steps 1 - 4 in PP bottles with a volume of $80 \mathrm{ml}$. The initial precursor suspensions before (step 1) and after partial evaporation of water (step 3) have weight of $18 \mathrm{~g}$ and $11 \mathrm{~g}$, respectively.

\subsection{Characterization}

Powder X-ray diffraction (XRD): The crystallinity of the powders sampled during the four-step syntheses are measured with a PANanalytical X'Pert Pro diffractometer using the $\mathrm{CuK} \alpha$ monochromatic radiation ( $\lambda$ $=1.5418 \AA$ ), in the $4-50^{\circ} 2 \theta$ range with a steps of $0.02^{\circ}$.

Transmission electron microscopy (TEM): The size, morphology and crystallinity of nanoparticles are determined by transmission electron microscopy (TEM) on a JEOL 2010 FEG operating at $200 \mathrm{kV}$.

Dynamic light scattering $(D L S)$ : The hydrodynamic diameters of amorphous and zeolite nanoparticles in water suspensions are determined with a Malvern Zetasizer Nano. The analyses take place after purification; the solid concentration of all suspensions is $2.5 \mathrm{wt} . \%$ at $\mathrm{pH}$ of 8 . The surface charge of nanocrystals is determined by measuring the zeta potential value on the same suspensions.

Nitrogen physisorption: Nitrogen $\left(\mathrm{N}_{2}\right)$ adsorption/desorption isotherms are measured on a Micromiretrics ASAP 2020 volumetric adsorption analyser. Samples are degassed overnight at $275{ }^{\circ} \mathrm{C}$ under vacuum prior to measurements. The external surface area and micropore volume are estimated by the alpha-plot method using Silica-1000 (22.1 $\mathrm{m}^{2} \mathrm{~g}^{-1}$ assumed) as a reference. The micropore and mesopore size distributions are estimated by the Nonlocal Density Functional Theory (NLDFT) and Barret-Joyner-Halenda (BJH) on the desorption branch, respectively.

Fourier-transform infrared (FTIR) spectroscopy: The IR spectra are recorded using a Nicolet 6700 spectrometer fitted with a DTGS detector (resolution 4, 128 scans; KBr: Sample= 100:1).

Raman spectroscopy: The spectra are recorded on a Jobin Yvon Labram 300 spectrometer fitted with a confocal microscope (Laser: $532 \mathrm{~nm}$, acquisition time: $240 \mathrm{~s}$ ). 
Liquid state ${ }^{29} \mathrm{Si}$ NMR: ${ }^{29} \mathrm{Si}$ NMR spectra are acquired on a Bruker AVIII HD 500MHz (11,7 Tesla) spectrometer operating at a ${ }^{29} \mathrm{Si}$ frequency of $99.3 \mathrm{MHz}$ equipped with a Bruker BBFO $5 \mathrm{~mm}$ NMR probe. All spectra were acquired using a ( $\pi / 6)$ single-pulse sequence with a pulse delay of $20 \mathrm{~s}$, an acquisition time of $3.17 \mathrm{~s}$ and a minimum of 512 scans. Prior to any measurement, $250 \mathrm{mg}$ of the zeolite suspensions are mixed with $1 \mathrm{~mL}$ Deuterium oxide $\left(\mathrm{D}_{2} \mathrm{O}\right)$ (mass ratio zeolite: $\left.\mathrm{D}_{2} \mathrm{O}=1: 4\right)$ in $5 \mathrm{~mm}$ Teflon tubes. The in situ

${ }^{29} \mathrm{Si}$ NMR study was performed on a Bruker AVIII HD $400 \mathrm{MHz}$ (9.4 Tesla) spectrometer equipped with a Bruker BBO $10 \mathrm{~mm}$ NMR probe, using $10 \mathrm{~mm}$ NMR FEP Teflon tubes. 256 scans were accumulated for each spectrum using a single $90^{\circ}$ excitation with a pulse length of $19 \mu \mathrm{s}$ and a recycle delay of $1 \mathrm{~s} .{ }^{29} \mathrm{Si}$ chemical shifts were referenced to tetramethylsilane (TMS) used as an internal standard.

$H P{ }^{129}$ Xe NMR spectroscopy: ${ }^{129}$ Xe NMR spectra are recorded on a Bruker Avance III- HD 400 (9.4 T) spectrometer at $110.6 \mathrm{MHz} ; 128$ scans are accumulated for each spectrum using a single $90^{\circ}$ excitation with a pulse length of $12.5 \mu \mathrm{s}$ and a recycle delay of $1 \mathrm{~s}$. The HP ${ }^{129} \mathrm{Xe}$ gas is produced on a home-built xenon polarizer based on the spin exchange optical pumping (SEOP) technique, ${ }^{[34]}$ capable to deliver a continuous flow of hyperpolarized ${ }^{129} \mathrm{Xe}$ directly to the sample. ${ }^{[35-36]}$ Prior to analysis, all samples are pressed under 100 MPa, then crushed and sieved to 200-500 $\mu \mathrm{m}$. The samples $(0.5 \mathrm{~g})$ are introduced in a home-designed $10 \mathrm{~mm}$ O.D. NMR tube and dehydrated under high vacuum $\left(10^{-6} \mathrm{mbar}\right)$ at $275^{\circ} \mathrm{C}$ overnight. $\mathrm{HP}^{129} \mathrm{Xe}$ NMR spectra

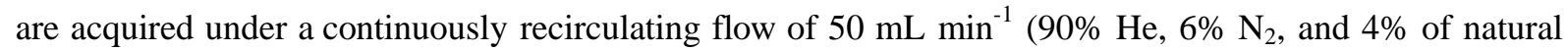
abundance xenon) at a pressure of $0.15 \mathrm{MPa}$. For all variable temperature (VT) measurements and after each temperature step (ramp rate of 5 C. $\mathrm{min}^{-1}$ ), 20 min elapse to ensure a homogeneous temperature all over the sample.

\section{Results and Discussion}

\subsection{From Highly Viscous Colloidal Suspension to Ultra-Small Zeolite Nanocrystals}

The synthesis of ultra-small FAU-type zeolites from OSDA-free precursor suspensions was fully described in the experimental section. Freshly prepared sodium aluminate supplies mainly monomeric aluminium species ${ }^{[37]}$ while colloidal silica dissolved in a sodium hydroxide solution provides monomeric and low molecular weight silica species. ${ }^{[24,29]}$ The two solutions A and B (see experimental section) are mixed at low temperature $\left(4^{\circ} \mathrm{C}\right)$ to decrease the rate of silica and alumina polymerization and thus providing highly homogeneous precursor suspensions with monomodal amorphous particles. During the preparation of the silicate solution (solution B), all sodium hydroxide is added to the silica source to achieve its complete dissolution. Sodium aluminate is highly soluble in water (Solution A) and our concentration (1.83 M; 0.56 $\mathrm{g}$ of $\mathrm{Al}_{2} \mathrm{O}_{3}$ in $3 \mathrm{ml} \mathrm{H} \mathrm{H}_{2} \mathrm{O}$ ) is lower than the solubility limit of alumina $(5 \mathrm{M})$. The size of the particles in solutions A and B, measured prior to mixing by DLS (Figure S1) is in the $0.8-1 \mathrm{~nm}$ range. The high alkalinity of the precursor suspension after mixing of the two solutions guarantees the formation of monodispersed amorphous particles. ${ }^{[24]}$ The resulting suspension is then aged for $24 \mathrm{hr}$ at RT and becomes water clear. The water content is further decreased in step 3, stabilizing highly concentrated amorphous particles in the supersaturated viscous media. The appearance of the amorphous precursor suspension (P-1), intermediates (P-2, P-3) and final crystalline suspension (FAU-24 h) in steps 1, 2, 3 and 4 is shown in Figure 2. After steps 1 and 2, both suspensions are fully transparent, while after partial evaporation of water 
(step 3), viscosity increases while transparency is preserved (Figure 2). Fully transparent suspensions with a high viscosity at step 3 and after step 4 (HT treatment) are obtained (Figure 2). The precursor suspension in step 3, containing alkali cations coordinated with water and/or silicate and aluminate species, has a high viscosity (Figure S2); this feature warrants to follow the mobility of sodium cations in the suspensions at each step by conductivity measurements.

P-1

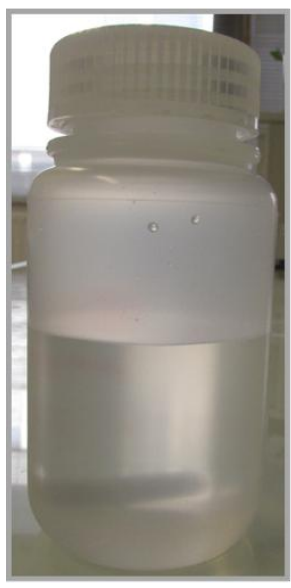

P-2

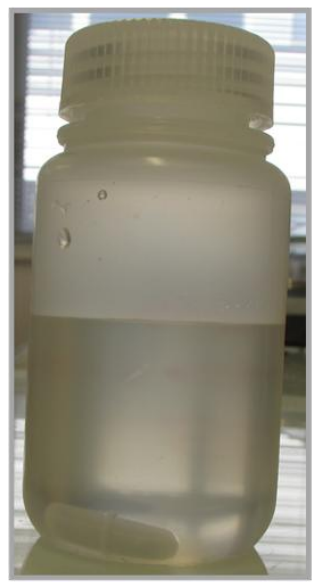

Amorphous
P-3

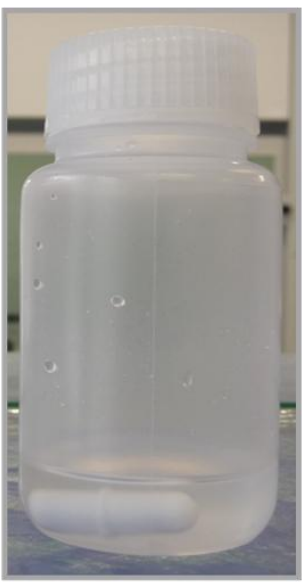

Crystalline
FAU-24 h

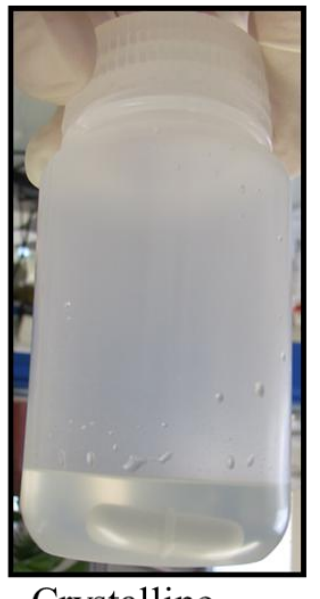

Figure 2. Precursor suspensions after mixing solutions A and B (step 1: P-1), after aging for 24 hr at RT (step 2: P-2), after partial evaporation of water (step 3: P-3) and after crystallization for $24 \mathrm{~h}$ at $50{ }^{\circ} \mathrm{C}$ (step 4: FAU-24 h).

Conductivity increases from step 1 to 2 (Figure 3A), as the silica remaining in suspension dissolves upon mixing and then decreases drastically from 61.3 to $3.5 \mathrm{mS} / \mathrm{cm}$ after partial evaporation of water indicating a lower sodium cations mobility (Figure 3). The amount of sodium trapped in the zeolite at the different steps is indirectly evaluated by measuring the $\mathrm{Al}$ content. As the $\mathrm{Si} / \mathrm{Al}$ ratio decreases during crystallization as the conductivity (Figure 3B), it is related to $\mathrm{Na}^{+}$trapping in proto-zeolitic materials (X-ray amorphous) already formed at the onset of crystallization.
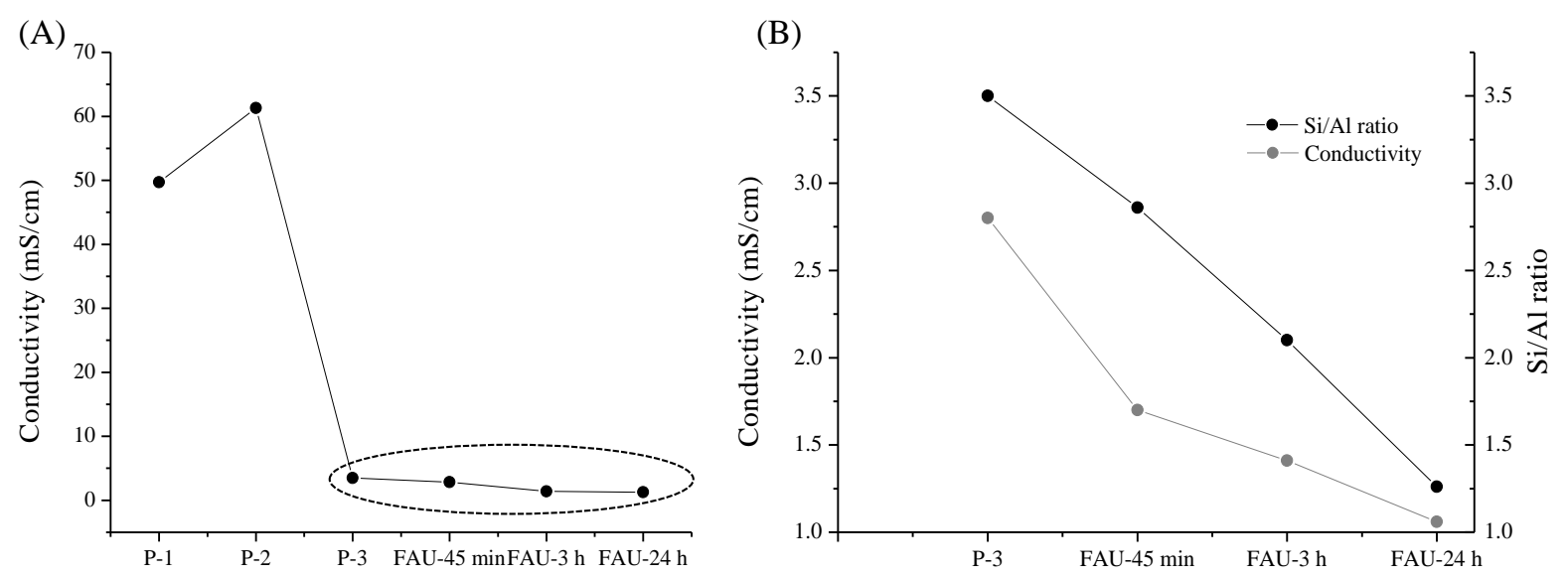

Figure 3. (A) Conductivity of precursor suspensions at different preparation steps (P-1, P-2, and P-3) and suspensions during crystallization at $50{ }^{\circ} \mathrm{C}$ (FAU-45 min, FAU-3 h, and FAU-24 h); (B) conductivity 
(grey) evolution of suspensions and $\mathrm{Si} / \mathrm{Al}$ ratio (black) of solid products of samples P-3 and FAU- 45 min, FAU-3 h and FAU-24 h.

The evolution of the crystallization of the zeolite nanoparticles is highlighted by XRD (Figure S3). The diffraction pattern of the precursor P-3 features a broad peak centred centered at $27^{\circ} 2 \theta$, typical of amorphous aluminosilicates. In the FAU-45 min pattern, peaks at 6.1, 11.7, 15.4, 23.5, 26.6 and $30.8^{\circ} 2 \theta$ indicate the emergence of X-ray visible FAU type zeolite. After a prolonged HT treatment ( 3 and $24 \mathrm{hrs}$ ), a fully crystalline FAU zeolite is obtained (Figure S3d). The crystalline yield of this sample is $65 \%$. The evolution of particle size, morphology and crystallinity is monitored by HRTEM (Figure 4). The TEM pictures of P-2 and P-3 both show similar regular amorphous particles, devoid of any lattice fringes, with a narrow size distribution around 15-20 nm (Figure 4a, b). FAU-45 min, harvested in step 4 after a 45 min hydrothermal treatment contains particles with fringes (Figure 4d) with a similar narrow size distribution around 10-20 nm. This implies that the P-2 and P-3 amorphous particles are converted in octahedrally shaped FAU crystals with similar dimensions (Figure 4e, f). The good agreement between TEM and DLS particle sizes (Figure 5) reinforces the occurrence of such a transformation where the size of the amorphous particles predetermines to a great extent the size of the ultimate zeolite crystals. 

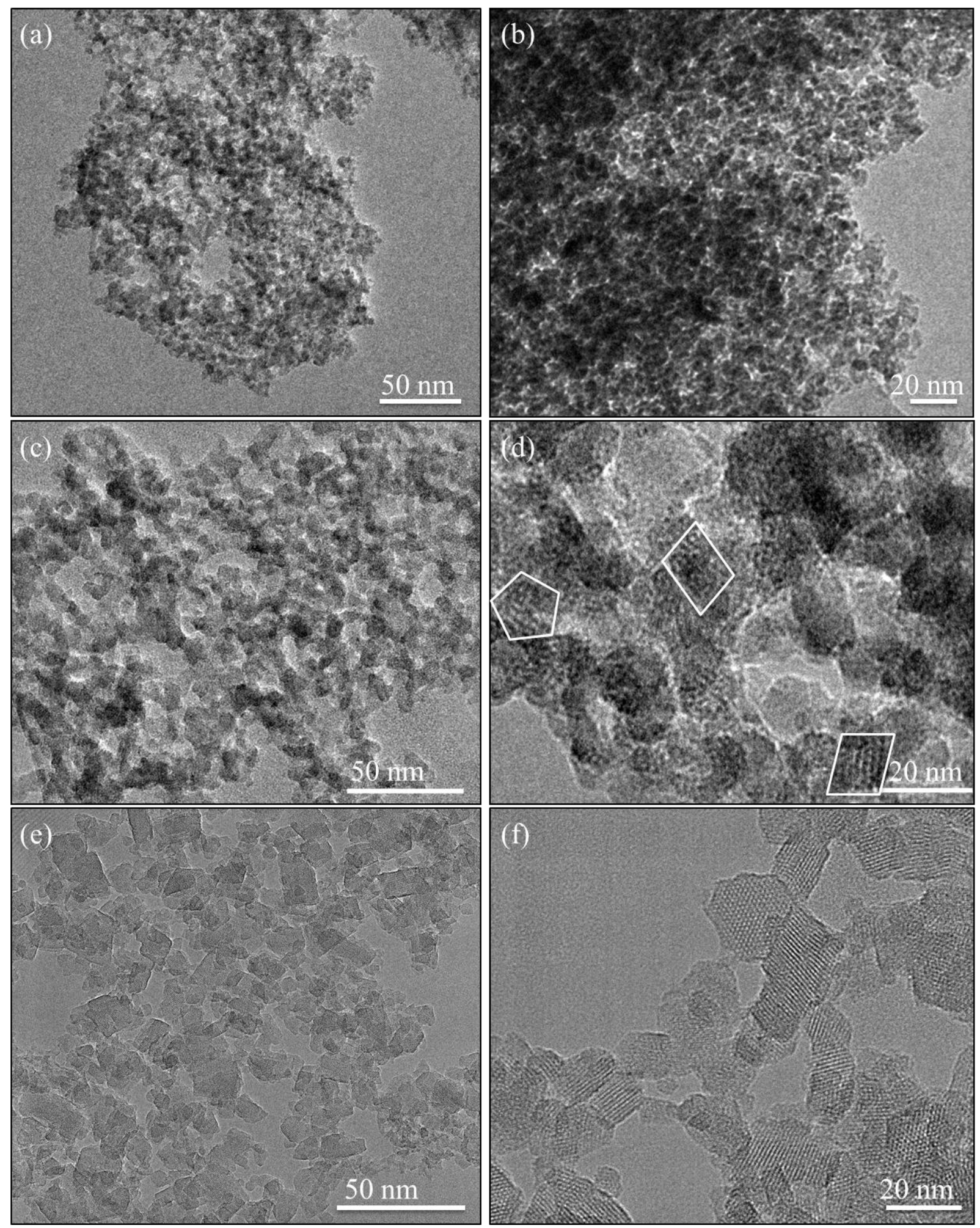

Figure 4. HRTEM images of (a) P-2, (b) P-3, (c, d) FAU-45min, and (e, f) FAU-24h. 


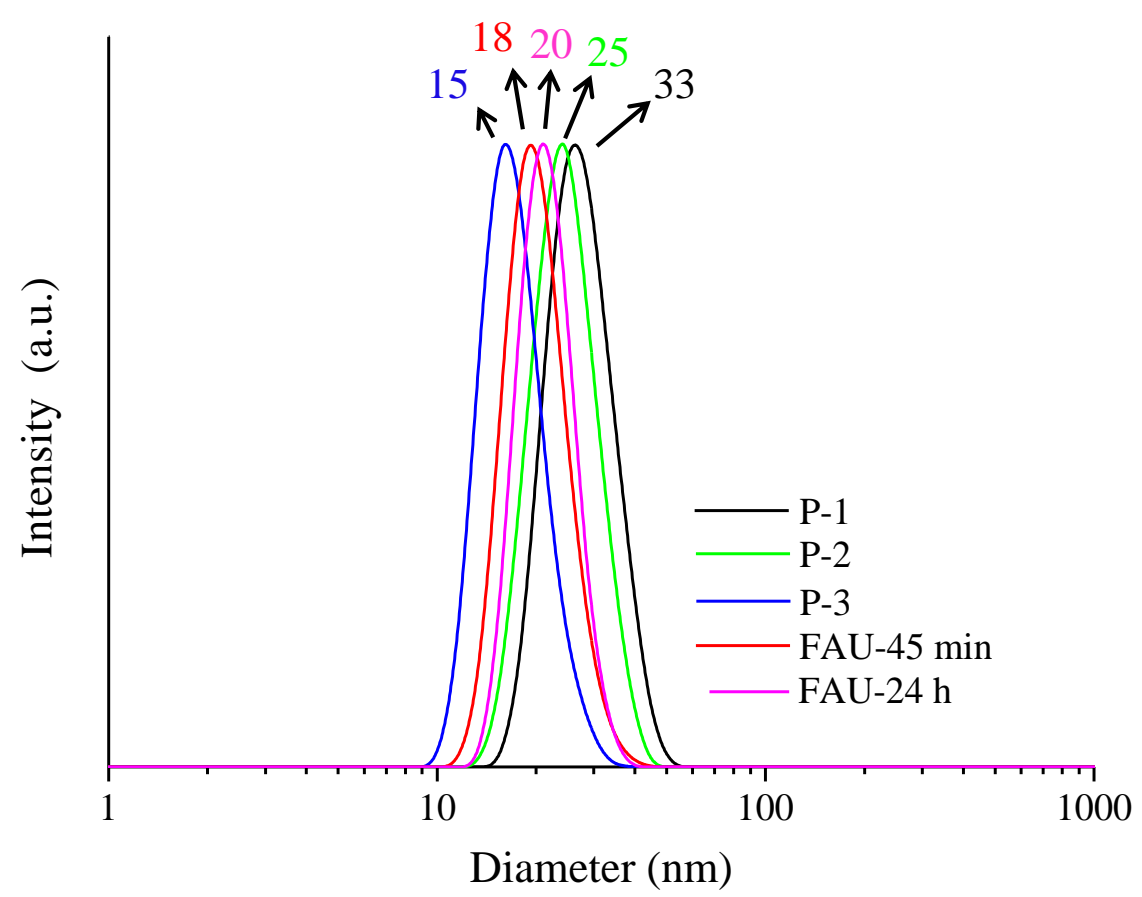

Figure 5. DLS particle size distribution of precursors (P-1, P-2, P-3) and crystalline zeolite suspensions (FAU-45 min and FAU-24 h).

As IR, NMR and Raman spectroscopies have demonstrated their potential to shed deeper insight on the short-range evolution of amorphous aluminosilicates to crystalline structures, they will be put to task in the next part, vide infra.

\subsection{Short-Range Order Evolution during Zeolite Crystallization - Spectroscopic Characterization} NMR Spectroscopy

Clear suspensions from the four crystallization steps are characterized by liquid state ${ }^{29} \mathrm{Si}$ NMR to identify the nature and evolution of the aluminosilicate species present (Figure S4). The main focus here is on the formation of the first secondary building units (SBU) of the FAU structure. ${ }^{[38]} \mathrm{A}$ previous ex-situ ${ }^{29} \mathrm{Si}$ MAS NMR study of the time evolution of hydrogels showed that only $\mathrm{Q}^{0}(4 \mathrm{Al})$ aluminosilicates are formed while colloidal silica dissolves in the rate-determining step. ${ }^{[27]}$ Upon mixing colloidal silica with sodium hydroxide at high $\mathrm{pH}$ and high temperature, monomeric silicate anions are formed. The evolution of the ${ }^{29} \mathrm{Si}$ NMR spectra of suspensions, from the pure silica solution B to the FAU-45 min is summarized in Figure S4. All ${ }^{29} \mathrm{Si}$ chemical shifts fall, as expected, in the -70 to $-120 \mathrm{ppm}$ range and Solution B (colloidal silica dissolved in aqueous $\mathrm{NaOH})$ displays the most complex spectra as all possible $\mathrm{Q}^{\mathrm{n}}(\mathrm{n}=1-4)$ environments are present (Figure S4a). For all samples, the spectra can be divided in 5 clusters, each one with overlapping $\mathrm{Q}^{\mathrm{n}}$ units and a distinct decreased intensity of the peaks associated with heavier units as crystallization progresses:

$\mathbf{Q}^{\mathbf{0}}$ : The lowest chemical shift (-71.2 ppm) corresponds to monomeric silica $\mathrm{Q}^{0}$ and is usually taken as the reference peak as its position is independent of the presence of other Si species; 
$\mathbf{Q}^{1} \mathbf{Q}^{2}$ : two sub-clusters are located between -76 and -83 ppm: (i) the one at -79.3 ppm, includes $\mathbf{Q}^{1}$ units in dimeric silicates and the slightly shifted peak of $\mathrm{Q}^{1}$ end groups, or $\mathrm{Q}^{1}$ connected with $\mathrm{Q}^{3}$ or $\mathrm{Q}^{4}$ units, and (ii) the other at $-80.4 \mathrm{ppm}$ is assigned to $\mathrm{Q}^{2}$ in trimeric cyclosilicates;

$\mathbf{Q}^{2} \mathbf{Q}^{3}$ : this cluster located between -86 and $-91 \mathrm{ppm}$ highlights the presence of a wide variety of $\mathrm{Q}^{2}$ units in P1 to FAU-45min: cyclotetrameric anions, the middle group of trimeric and tetrameric chain silicates, $\mathrm{Q}^{2}$ units in substituted cyclosilicates and di- and tri-cyclic structures. ${ }^{[39]}$ Some $\mathrm{Q}^{3}$ units are also present, but only in solution B;

$\mathbf{Q}^{\mathbf{3}}$ : these peaks catered around - $96 \mathrm{ppm}$ are only observed in solution B;

$\mathbf{Q}^{4}$ : this broad line around $-110 \mathrm{ppm}$ belongs to bulky $\mathrm{Q}^{4}$ units difficult to detect in liquid-state NMR as their molecular weight put them more in the domain of solid-state NMR.

Some representative silicate species of P-1 suspension are listed and attributed in Table S1. ${ }^{[40]}$

The ${ }^{29} \mathrm{Si}$ NMR spectra of the pristine colloidal suspensions and solution B (silica solution) are recorded following the experimental protocol outlined in Figure S5. P-1 spectra are recorded every 5 min during the $24 \mathrm{~h}$ aging at $25^{\circ} \mathrm{C}$ (Figure 6) as well those of P-2 and P-3. P3 is the heated to $50^{\circ} \mathrm{C}$ and spectra collected every 5 min during the $24 \mathrm{~h}$ crystallization. Three important features of these in-situ ${ }^{29} \mathrm{Si}$ NMR spectra arise:

1) the appearance of new peaks at -76 and $-83 \mathrm{ppm}$ in $\mathrm{P} 1, \mathrm{P} 2$ and $\mathrm{P} 3$ due the formation of solid particles and/or exchange between the solid and liquid phase. They disappear upon heating at $50{ }^{\circ} \mathrm{C}$ (Figure $6 \mathrm{e}, \mathrm{f}, \mathrm{g})$ due to fast exchange between the silica from the solids $(-76 \mathrm{ppm})$ and the monomer silica species (-72 ppm). The dynamics of the solid-liquid and/or liquid-liquid exchange is highlighted in a NOESY (Nuclear Overhauser Effect Spectroscopy) 2D spectra (Figure S6).

2) The $-72 \mathrm{ppm}$ peak width at half-height $(\Delta)$ increases from P-1 ( $\Delta=1.85 \mathrm{ppm}), \mathrm{P}-2$ ( $\Delta=1.9 \mathrm{ppm})$ and P-3 ( $\Delta=2.02 \mathrm{ppm})$ to level from FAU-45 min onwards ( $\Delta=2.15 \mathrm{ppm})$. The formation of proto-zeolitic materials in $\mathrm{P}-2$, with a chemical composition similar to the final crystalline material rationalizes such a behaviour.

3) The -94.8 ppm peak, assigned to the formation of double-six rings (D6R), shifts to lower values as $\mathrm{Al}$ is incorporated in the zeolite (Figure 6). 


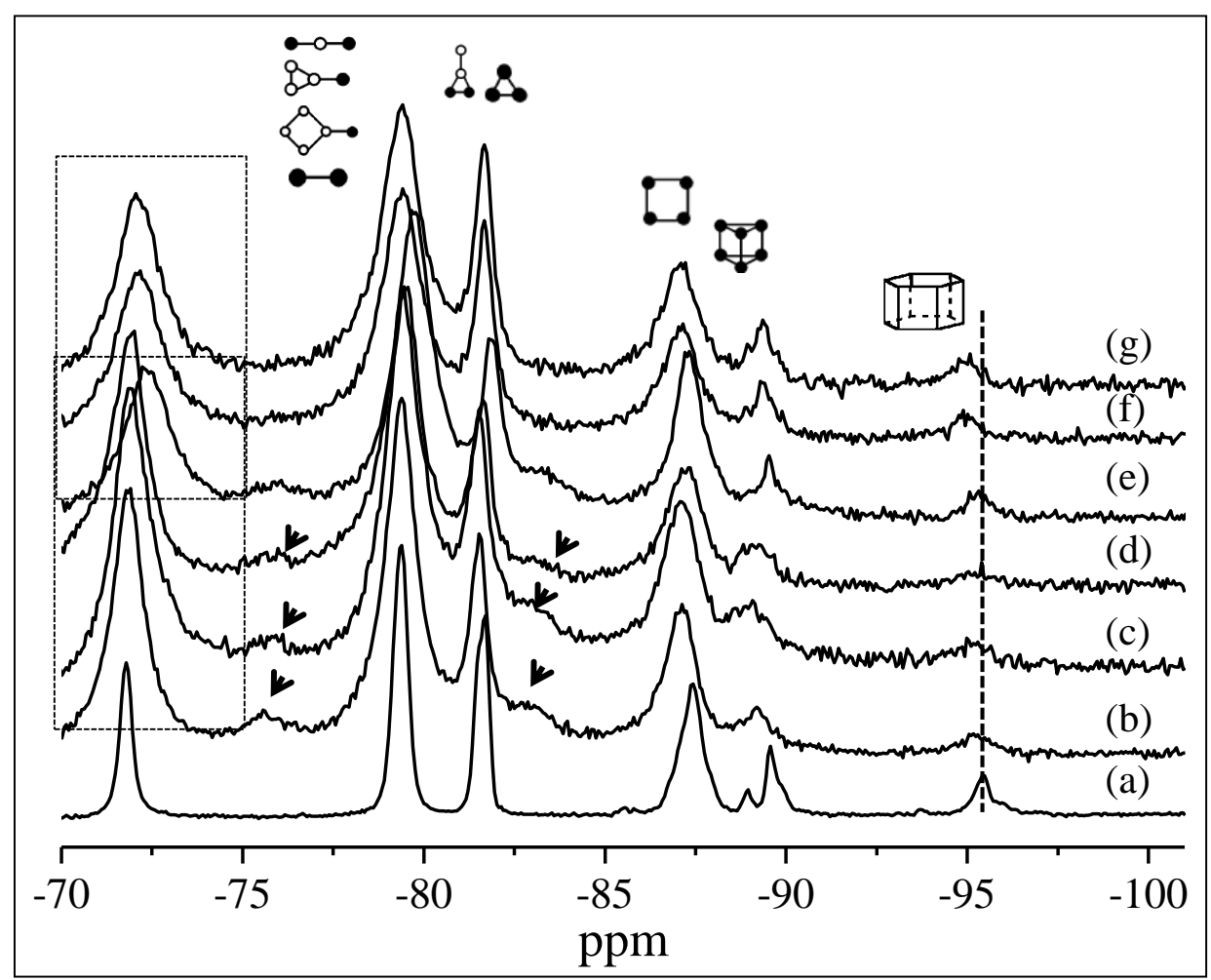

Figure 6. In-situ liquid state ${ }^{29} \mathrm{Si}$ NMR spectra of (a) solution B, (b) P-1, (c) P-2, (d) P-3, (e) FAU-45min, (f) FAU-3h and (g) FAU-24h.

\section{FT-IR Spectroscopy}

Additional evidence for the formation of D6R upon aging (P-2) and further evaporation of water (P-3) of the precursor suspension P1 comes from FT-IR spectroscopy study. The P-3, FAU-45 min, FAU-3 h, and FAU-24 h spectra are gathered in Figure 7. The main changes appear in the 1250-920 $\mathrm{cm}^{-1}$ (asymmetrical stretching T-O-T vibration), 720-650 $\mathrm{cm}^{-1}$ (symmetrical stretching T-O-T mode), and 500-420 $\mathrm{cm}^{-1}$ (T-O bending mode of the $\mathrm{TO}_{4}$ tetrahedra) regions. The D6R ring breathing mode band at $575 \mathrm{~cm}^{-1}$ in X-ray amorphous P-3 shifts to lower wave numbers on FAU-45min $\left(566 \mathrm{~cm}^{-1}\right)$, becomes more resolved and slightly shifts to $562 \mathrm{~cm}^{-1}$ on FAU-3h and further increases in intensity on FAU-24h (Figure 7). That this D6R band appears even in P-3, i.e. before any mild hydrothermal treatment indicates that ultra-small zeolite nanoparticles (proto zeolitic crystals) are already present so early in the crystallization process. 


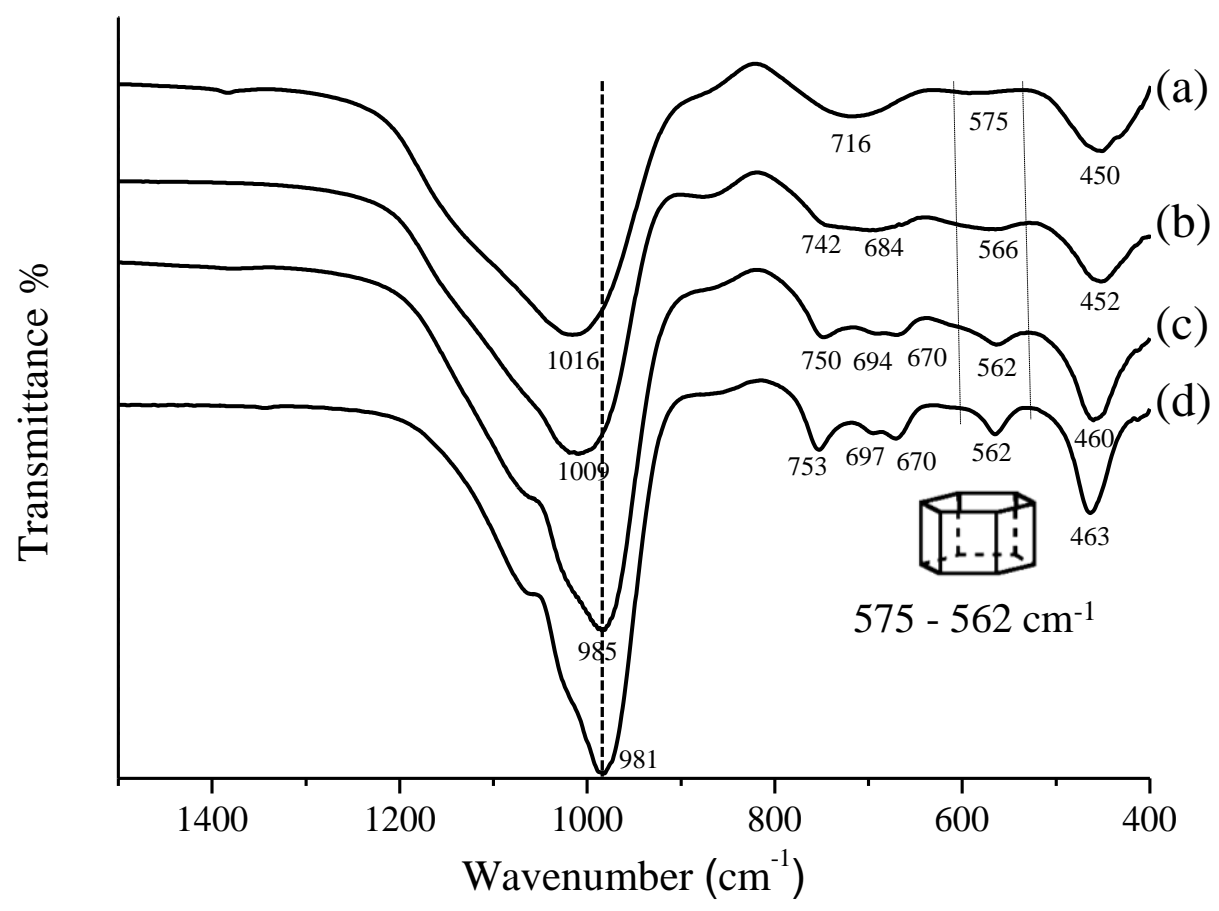

Figure 7. IR spectra of (a) P-3, (b) FAU-45 min, (c) FAU-3 h, (d) FAU-24 h in the $400-1500 \mathrm{~cm}^{-1}$ window.

Both ${ }^{29} \mathrm{Si}$ NMR, vide supra, and FT-IR reveal presence of double six-ring (D6R) secondary building unit (SBU) of the FAU structure in P-3, i.e., as early as step 3 of the zeolite crystallization.

\section{Raman and Solid-State NMR Spectroscopy}

Raman spectroscopy can complement such a study of the early stages of zeolite formation (Figure 8). The peaks at 501, 855 and $1020 \mathrm{~cm}^{-1}$ characteristic of amorphous aluminosilicates are present in the spectrum of P-1 (Figure 8a). The broad band centred around $501 \mathrm{~cm}^{-1}$ is assigned to out of plane bending Si-O-Si mode typical for amorphous polymeric silicates. After aging and partial evaporation of water (P-3), the bands at $296 \mathrm{~cm}^{-1}$ (six-membered rings) and $504 \mathrm{~cm}^{-1}$ (four-membered rings) narrow relative to P-1 (Figure 8c). The $865 \mathrm{~cm}^{-1}$ band, assigned to the symmetric T-O stretching mode, does not change significantly while the 970-1064 $\mathrm{cm}^{-1}$ bands, attributed to the asymmetric T-O-T stretching mode evolve. This suggests that species containing both four- and six-membered rings are present in P-3. For FAU-45min, the broad band at $504 \mathrm{~cm}^{-1}$ narrows and shifts to $506 \mathrm{~cm}^{-1}$ (Figure 8d). At the same time, bands appear at $287 \mathrm{~cm}^{-1}$ and 381 $\mathrm{cm}^{-1}$, assigned to D6R, while the $1020 \mathrm{~cm}^{-1}$ band splits in two bands at $997 \mathrm{~cm}^{-1}$ and $1064 \mathrm{~cm}^{-1}$ both characteristic of zeolite $\mathrm{X}^{[41-43]}$ The appearance of a broad band at $1020 \mathrm{~cm}^{-1}$ in P-2 and P-3 is significant (Figure $8 \mathrm{~b}, \mathrm{c}$ ) as this can be due to the formation of the $\beta$ (SOD) cages expected for zeolite X. Sodalite cages possess both $4 \mathrm{MR}$ and $6 \mathrm{MR}$, but the framework of zeolite $\mathrm{X}$ has not yet been formed at this stage and the different oxygen positions may be resolved only for the fully crystalline zeolite, FAU-24h. All Raman bands become more intense and narrower after hydrothermal treatments between 45 min and $6 \mathrm{~h}$ (Figure 8e) and indicate that crystallization is complete after $24 \mathrm{~h}$ (FAU-24h). The bands corresponding to the formation of SOD cages connected via the double six-membered rings (290 and $380 \mathrm{~cm}^{-1}$ ) already appear in FAU-45 min (Figure 8d). 


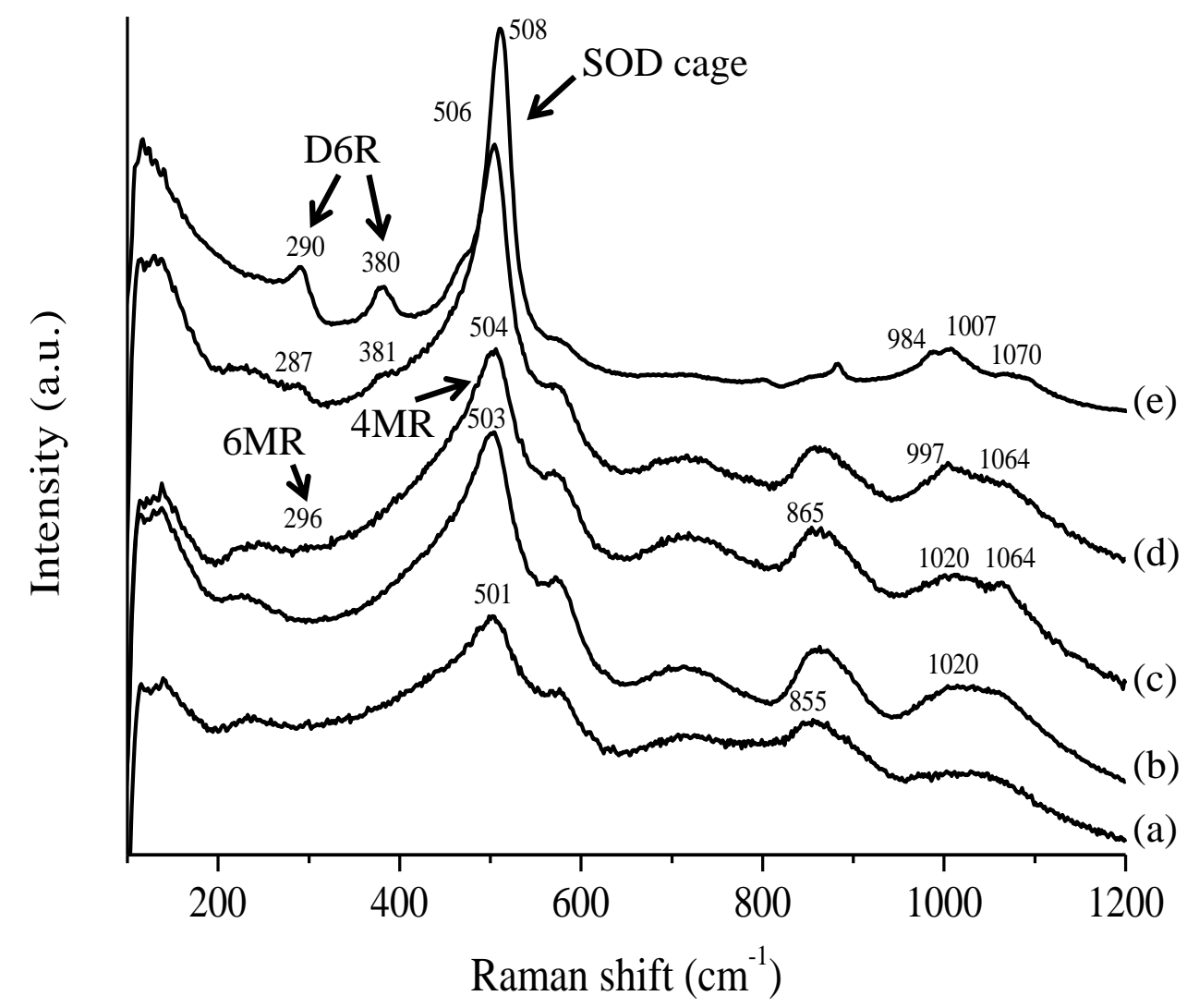

Figure 8. Raman spectra of (a) P-1, (b) P-2, (c) P-3, (d) FAU-45 min, and (e) FAU-24 h.

${ }^{29} \mathrm{Si}$ solid-state NMR spectroscopy on the same series of materials (Figure 9) will determine Si/Al ratio changes during the crystallization process. As expected, the silica species exist as monomeric and oligomeric anions formed from $\mathrm{SiO}_{4}$ tetrahedra in P-1. A broad asymmetric signal at $-88.0 \mathrm{ppm}$ is observed in the spectrum and can be divided in two entities corresponding to mono- and oligomeric species, respectively. The dmfit method ${ }^{[27]}$ is applied to fit the spectra based on the Engelhardt and Michel equation. The ${ }^{29}$ Si MAS NMR spectra of fully crystalline samples contain five peaks at -84.4, -89.0, -94.1, -99.0, and $-104.3 \mathrm{ppm}$ attributed to $\mathrm{Q}^{4}(4 \mathrm{Al}), \mathrm{Q}^{4}(3 \mathrm{Al}), \mathrm{Q}^{4}(2 \mathrm{Al}), \mathrm{Q}^{4}(1 \mathrm{Al})$, and $\mathrm{Q}^{4}(0 \mathrm{Al})$, respectively. The degree of crystallinity of all samples calculated by ${ }^{29} \mathrm{Si}$ NMR are summarized in Table $\mathrm{S} 2$. The formation of the FAU structure in the P-2 sample is confirmed by the appearance of $\mathrm{Q}^{4}(4 \mathrm{Al})$ to $\mathrm{Q}^{4}(0 \mathrm{Al})$ peaks superimposed to the broad signal coming for the amorphous material necessary to perfectly fit spectrum. The Si/Al ratio of P-1 cannot be measured since the spectrum is dominated by silicon species in an amorphous phase. In P-3 (suspension after partial evaporation of water), the $\mathrm{Si} / \mathrm{Al}$ ratio is estimated to be 2.8 . After hydrothermal treatment the Si/Al ratio of FAU-45 min, FAU-3 h and FAU-24 h decreases from 1.7 to 1.41 and 1.06, respectively (Figure 9). The ${ }^{29} \mathrm{Si}$ NMR signals in the fully crystalline FAU-24 h are symmetric and sharp, implying high homogeneity. We can therefore suggest that the crystallization of FAU zeolite starts during the partial evaporation of water step of the precursor suspension (P-3), in agreement with the FTIR results, where the formation of the D6R is observed. 


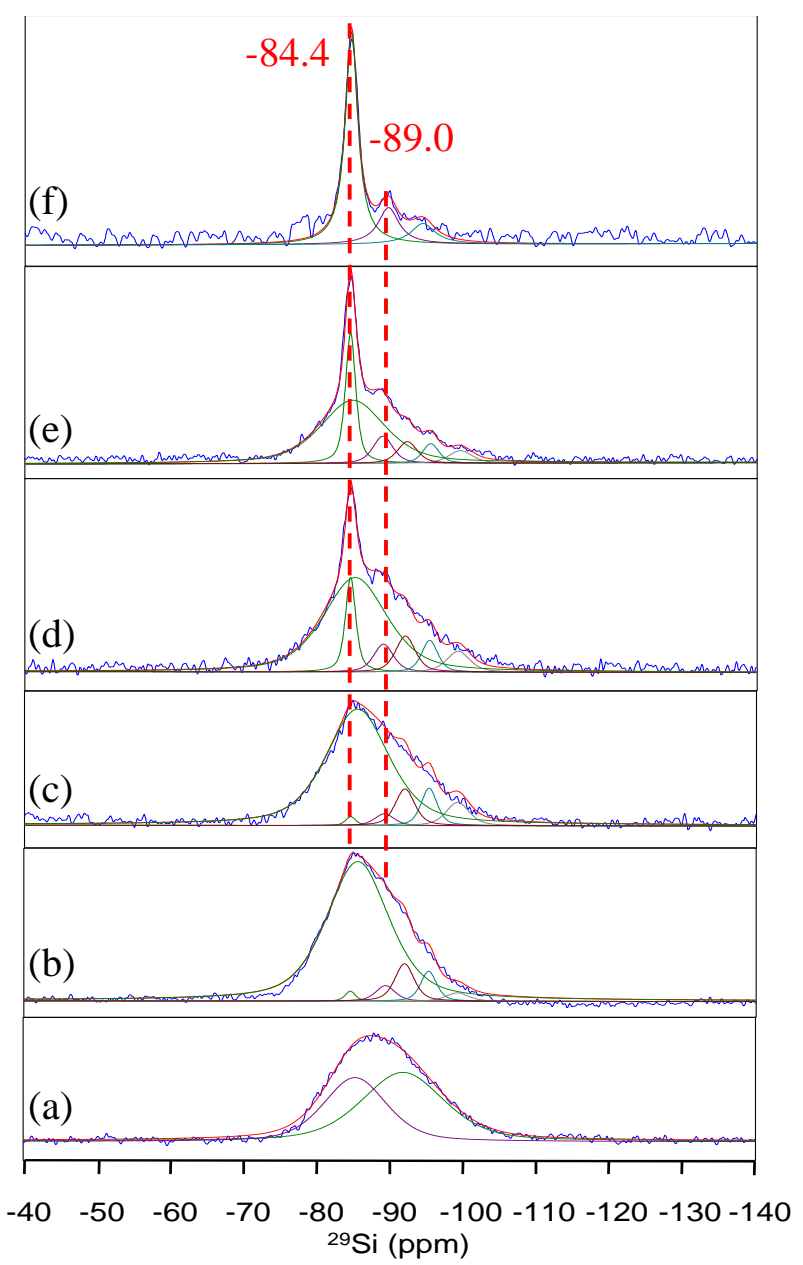

Figure 9. ${ }^{29}$ Si NMR spectra of (a) P-1, (b) P-2, (c) P-3, (d) FAU-45 min, (e) FAU-3 h and (f) FAU-24 h.

\subsection{Long-Range Crystalline Order and Porosity}

$H P^{129}$ Xe NMR Spectroscopy

The development of the porosity of the samples at steps $1-4$ was studied by HP ${ }^{129}$ Xe NMR (Figure 10). The HP ${ }^{129} \mathrm{Xe}$ NMR spectrum of P-1 (Figure 10a) contains a broad peak at $50 \mathrm{ppm}$ corresponding to Xenon in a confined space with a non-defined porosity. Another narrow peak appears at $78 \mathrm{ppm}, 80 \mathrm{ppm}$ and 82 ppm for P-3, FAU-45 min and FAU-3 h, respectively (Figure 10). The evolution of this peak is consistent with the partial crystallization of these samples as a higher chemical shift is associated with xenon located in a confined environment. The spectrum of the fully crystalline FAU-24 h contains two peaks at 77.5 and $82.5 \mathrm{ppm}$, assigned to ${ }^{129} \mathrm{Xe}$ located in the sodalite cages and supercages, respectively (Figure $10 \mathrm{e})$. 


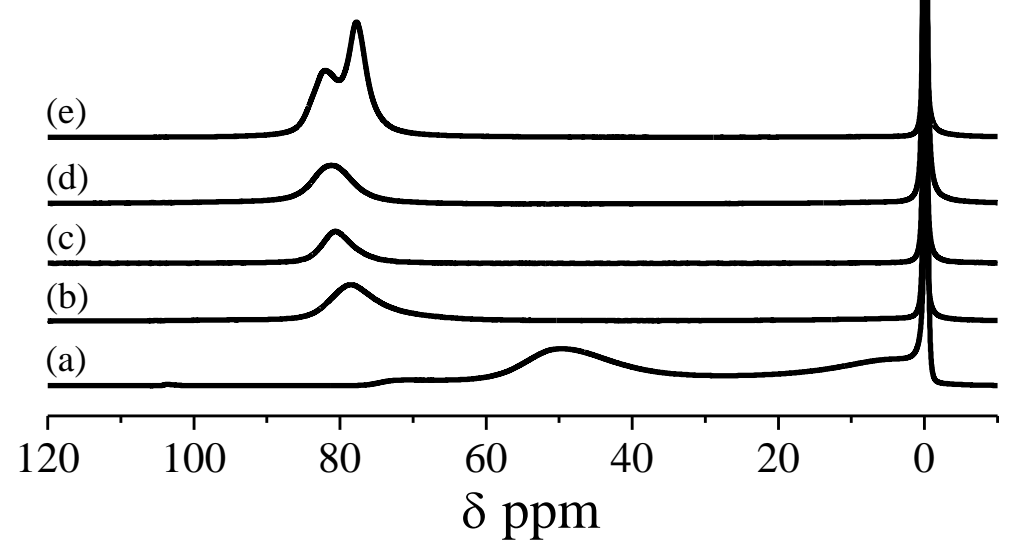

Figure 10. HP ${ }^{129}$ Xe NMR spectra of (a) P-1, (b) P-2, (c) FAU-45 min, (d) FAU-3 h and (e) FAU-24 h.

To verify the assignment of these two chemical shifts, the HP ${ }^{129} \mathrm{Xe}$ spectrum of the as-synthesized FAU$24 \mathrm{~h}$ is compared with that of ion-exchanged derivative with $\mathrm{Li}$ (sample Li-FAU-24 h). FAU-24 $\mathrm{h}$ is partially exchanged (70\%) with the smaller cation (ionic radii: $\mathrm{Li}^{+}=0.6 \AA, \mathrm{Na}^{+}=0.95 \AA$ ). The 82.5 ppm peak is present in both the FAU-24 h and Li-FAU-24 h spectra, while the $77.5 \mathrm{ppm}$ peak in the FAU-24 $\mathrm{h}$ spectrum shifts to $74.5 \mathrm{ppm}$ (Li-FAU-24 h) after Li ion-exchange (Figure 11b); the smaller Li cation located in the supercages increasing the available volume in the latter.

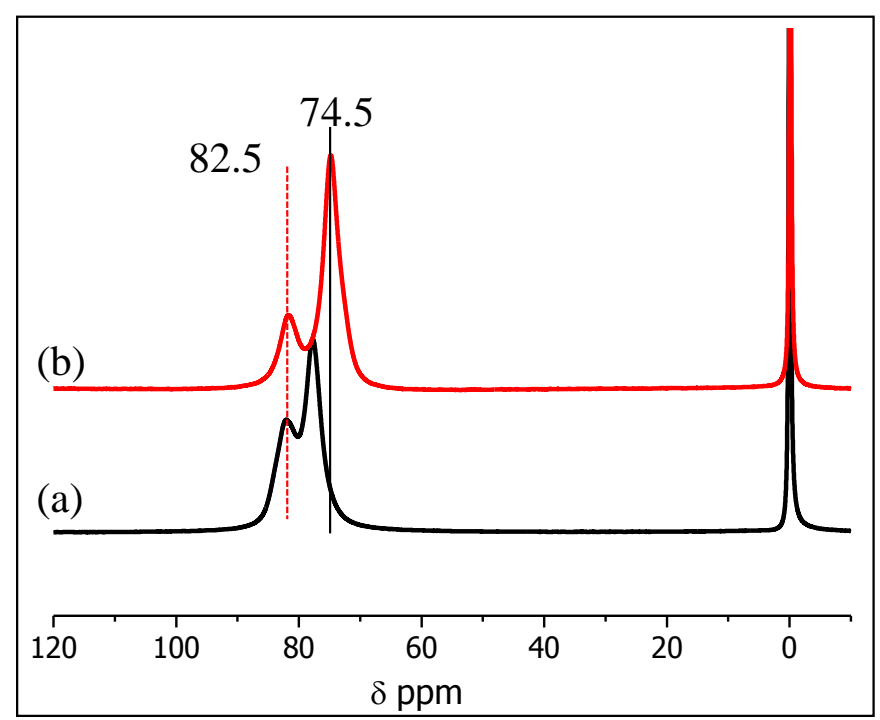

Figure 11. HP ${ }^{129} \mathrm{Xe}$ NMR spectra of (a) FAU-24 $\mathrm{h}$ and (b) Li-FAU-24 h.

Xe, with a kinetic diameter of $4.4 \AA$ does not enter in the sodalite cages as the opening of its entrance is only $4 \AA$ A. However, on ultra-small FAU nanosized zeolite, sodalite cages and supercages located on the external surface of the crystals are partially opened. Surface defects due to missing $\mathrm{T}$ atoms in the 
hexagonal prisms may facilitate the penetration of Xe into sodalite cages and its subsequent diffusion in the microporosity as was recently reported by our group ${ }^{\text {[44] }}$

\section{Nitrogen Adsorption}

The development of the porosity in the samples is monitored by $\mathrm{N}_{2}$ physisorption. The formation of a proto zeolitic material in P-3, i.e., X-ray amorphous but with well-defined particles containing micropores is confirmed. P-3 has the highest external surface area $\left(S_{\mathrm{ext}}=300 \mathrm{~m}^{2} / \mathrm{g}\right)$ and its isotherm is a mix of types I (micropore) and IV (mesopore) with a large H1 hysteresis (Figure 12). Such features are associated with textural pores formed by the close packing of monodispersed nanosized particles. The presence of microporosity at this stage indicates the formation of some unit cells corresponding to FAU zeolite. The degree of crystallinity in the samples increases with hydrothermal treatment and correlates well with the gradual increase of the micropore volume from 0.10 to $0.31 \mathrm{~cm}^{3} / \mathrm{g}$ (Table 1). The FAU-24 h micropore volume is comparable to that of micron-sized FAU. All samples have well developed textural mesoporosity confirming that the particle sizes in the amorphous, intermediates and final crystalline samples are very similar (Table S2).

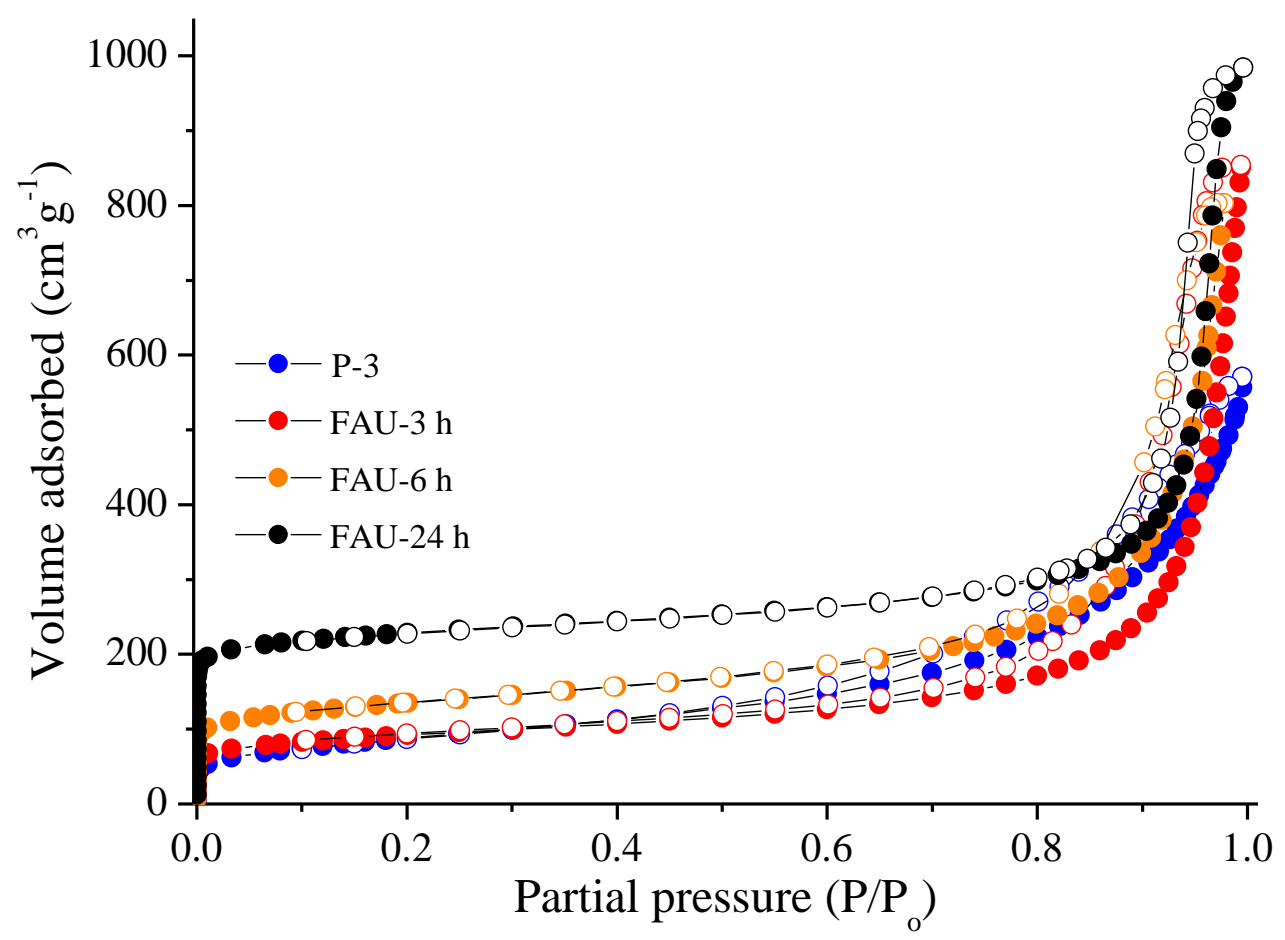

Figure 12. $\mathrm{N}_{2}$ sorption isotherms of samples P-3, FAU-3 h, FAU-6 h and FAU-24 h.

Table 1. $\mathrm{N}_{2}$ sorption data of samples obtained at different crystallization steps. 


\begin{tabular}{llllll}
\hline Samples & $\begin{array}{l}\mathbf{S}_{\text {BET }} \\
\left(\mathbf{m}^{2} / \mathbf{g}\right)\end{array}$ & $\begin{array}{l}\mathbf{V}_{\text {mic }} \\
\left(\mathbf{c m}^{3} / \mathbf{g}\right)\end{array}$ & $\begin{array}{l}\mathbf{V}_{\text {mes }} \\
\left(\mathbf{c m}^{3} / \mathbf{g}\right)\end{array}$ & $\begin{array}{l}\mathbf{S}_{\text {ext }} \\
\left(\mathbf{m}^{2} / \mathbf{g}\right)\end{array}$ & $\begin{array}{l}\mathbf{V}_{\text {tot }} \\
\left(\mathbf{c m}^{3} / \mathbf{g}\right)\end{array}$ \\
\hline FAU-24 h & 870 & 0.31 & 1.23 & 270 & 1.54 \\
FAU-6 h & 500 & 0.17 & 1.12 & 225 & 1.29 \\
FAU-3 h & 390 & 0.10 & 1.21 & 185 & 1.31 \\
P-3 & 350 & 0.05 & 0.83 & 300 & 0.88 \\
\hline
\end{tabular}

\section{Conclusion}

The crystallization of OSDA-free FAU nanocrystals was followed using several complimentary characterization methods well suited for tracking zeolite synthesis. The transformation pathway from a viscous amorphous precursor suspension to fully crystalline zeolite suspensions is elucidated by measuring the mobility of the $\mathrm{Na}$ cations and their subsequent trapping in the zeolite structure alongside the incorporation of $\mathrm{Al}$ in the zeolite framework. The formation of the very first SBUs (D6R) was demonstrated by FTIR and in-situ ${ }^{29} \mathrm{Si}$ NMR. We demonstrated that the clear precursor suspension formed during the mixing time undergoes substantial chemical and morphological changes during the aging and partial evaporation of water steps, where the stoichiometric composition is achieved. In addition, the size of the amorphous nanoparticles in the initial precursor suspension and their transformation in crystalline nanoparticles is set by the preparation parameters (temperature, speed of mixing, aging). A high alkalinity of the suspensions produces precursors with high surface area and ultra-small sizes. In-situ ${ }^{29} \mathrm{Si}$ NMR spectroscopy indicates the formation and the nature of $\mathrm{Q}^{3}$ and $\mathrm{Q}^{4}$ silicate species surrounded by $\mathrm{Q}^{1}$ and substituted $\mathrm{Q}^{2}$ silicate species. Liquid state ${ }^{29} \mathrm{Si}$ NMR spectroscopy also indicates the existence of D6R prior to hydrothermal treatment (P-3) while solid state ${ }^{29} \mathrm{Si}$ NMR spectroscopy tracks the evolution of the FAU crystallization. A key finding, provided by $2 \mathrm{D} \mathrm{HP}{ }^{129} \mathrm{Xe}$ EXSY, highlights the structural flexibility of nanosized FAU zeolites leading to a faster molecular traffic between the two different cages in this structure is worth considering in many applications (catalysis, separations by adsorption) for nanosized zeolites.

The methodology outlined is applicable to better design many other zeolites where nanosized crystals prove useful.

\section{Acknowledgements}

This research was supported by UOP-Honeywell.

\section{References}

[1] W. Vermeiren, J.-P. Gilson, Top. Catal. 2009, 52, 1131-1161.

[2] M. J. Climent, A. Corma, S. Iborra, Chem. Rev. 2011, 111, 1072-1133.

[3] D. E. De Vos and P. A. Jacobs, Micropor. Mesopor. Mater. 2005, 82, 293-304. 
[4] P. A. Jacobs, M. Dusselier, B. F. Sels, Angew. Chem. Int. Ed. 2014, 53, 8621-8626.

[5] P. Y. Dapsens, C. Mondelli, J. Perez-Ramirez, ACS Catal. 2012, 2, 1487-1499.

[6] T. P. Lee, B. Saad, E. P. Ng, B. Salleh, Chromatogr. A 2012, 1237, 46-54.

[7] M. Li, J. Hüve, C. Krampe, G. Luppi, M. Tsotsalas, J. Klingauf, L. De Cola, K. Riehemann, Small 2013, 9, 1809-1820.

[8] http://www.iza-structure.org/databases/.

[9] (a) M. Choi, K. Na, J. Kim, Y. Sakamoto, O. Terasaki, R. Ryoo, Nature 2009, 461, 246-249. (b) J-P Gilson, in: Zeolite Microporous Solids: Synthesis, Structure, and Reactivity, E.G. Derouane, F. Lemos, C. Naccache, F.R. Ribeiro (eds), Springer, Dordrecht, 1992, https://doi.org/10.1007/978-94-011-2604-5_2)

[10] K. Na, C. Jo, J. Kim, K. Cho, J. Jung, Y. Seo, R.J. Messinger, B.F. Chmelka, R. Ryoo, Science 2011, 333, 328-332.

[11] Z. Lai, G. Bonilla, I. Diaz, J.G. Nery, K. Sujaoti, M.A. Amat, E. Kokkoli, O. Terasaki, R.W.

Thompson, M. Tsapatsis, D.G. Vlachos, Science 2003, 300, 456-460.

[12] X. Y. Zhang, D. X. Liu, D. D. Xu, S. Asahina, K. A. Cychosz, K. V. Agrawal, Y. Al Wahedi, A.

Bhan, S. Al Hashimi, O. Terasaki, M. Thommes, M. Tsapatsis, Science 2012, 336, 1684-1687.

[13] M. K. Choudhary, R. Jain, J. D. Rimer, PNAS 2020, 117, 28632-28639.

[14] R. Li, N. Linares, J. G. Sutjianto, A. Chawla, J. Garcia-Martinez, J. D. Rimer, Angew. Chem. 2020, 57, 11283-11288.

[15] M. D. Oleksiak, J. A. Soltis, M. T. Conato, R. L. Penn, J. D. Rimer, Chem. Mater. 2016, 28, 49064916.

[16] V. P. Valtchev, K. N. Bozhilov, J. Phys. Chem. B 2004, 108, 15587-15598.

[17] M. Tsapatsis, M. Lovallo, T. Okubo, M. E. Davis, M. Sadakata, Chem. Mater. 1995, 7, 1734-1741.

[18] O. Larlus, V. P. Valtchev, Chem. Mater. 2004, 16, 3381-3389.

[19] S. Mintova, N. H. Olson, J. Senker, T. Bein, Angew. Chem. 2002, 41, 2558-2561.

[20] I. Yordanov, R. Knoerr, V. De Waele, M. Mostafavi, Ph. Bazin, S. Thomas, M. Rivallan, L. Lakiss, T. H. Metzger, S. Mintova, J. Phys. Chem. C 2010, 114, 20974-20982.

[21] V. P. Valtchev, L. Tosheva, K. N. Bozhilov, Langmuir 2005, 21, 10724-10729.

[22] L. Dimitrov, V. Valtchev, D. Nihtianova, Y. Kalvachev, Cryst. Growth Design. 2011, 11, 4958-4962.

[23] E.-P. Ng, D. Chateigner, T. Bein, V. Valtchev, S. Mintova, Science 2012, 335, 70-73.

[24] H. Awala, J-P. Gilson, R. Retoux, P. Boullay, J-M. Goupil, V. Valtchev, S. Mintova, Nature Mater. 2015, 14, 447-451.

[25] J. Grand, N. Barrier, M. Debost, E. B. Clatworthy, F. Laine, P. Boullay, N. Nesterenko, J.-P. Dath, J.P. Gilson, S. Mintova, Chem. Mater. 2020, 32, 5985-5993.

[26] M. Debost, P. B. Klar, N. Barrier, E. B. Clatworthy, J. Grand, F. Laine, P. Brázda, L. Palatinus, N. Nesterenko, P. Boullay, S. Mintova, Angew. Chem. 2020, 59, 23491-23495.

[27] G. Engelhardt, D. Michel, Wiley \& Sons, New York, 1987.

[28] J. Grand, H. Awala, S. Mintova, CrystEngComm. 2016, 18, 650-664.

[29] M. Kumar, M. K. Choudhary, J. D. Rimer, Nat. Commun. 2018, 9, 2129.

[30] F. Schüth, Curr. Opin. Solid State Mater. Sci. 2001, 5, 389-395. 
[31] F. Wang, V. N. Richards, S. P. Shields, W. E. Buhro, Chem. Mater. 2014, 26, 1, 5-21.

[32] S. Mintova, H. Awala, J.-P. Gilson, V. Valtchev, Patent, US20160325271A1

[33] M. Maldonado, M. D.Oleksiak, S.Chinta, J. D. Rimer, J. Am. Chem. Soc. 2013, 135, 2641-2652.

[34] El Siblani, H. Applications de la RMN du 129Xe hyperpolarisé à l'analyse de matériaux poreux. Ph.D. thesis, Université de Caen - Normandie, France, 2016.

[35] W. Happer, E. Miron, S. Schaefer, D. Schreiber, W. A. van Wijngaarden, X. Zeng, Physical Rev. A 1984, 29, 3092-3110.

[36] D. Massiot, F. Fayon, M. Capron, I. King, S. Le Calvé, B. Alonso, J.- O. Durand, B. Bujoli, Z. Gan, G. Hoatson, Magn. Reson. Chem. 2002, 40, 70-76.

[37] R. M. Barrer, Academic Press, London, 1982.

[38] D.M. Ginter, A. T. Bell, C. J. Radke, Zeolites 1992, 12, 742-749.

[39] A. Depla, D. Lesthaeghe, T. S. van Erp, A. Aerts, K. Houthoofd, F. Fan, C. Li, V. Van Speybroeck, M. Waroquier, C. E. A. Kirschhock, J. A. Martens, J. Phys. Chem. C 2011, 115, 3562-3571.

[40] M. T. Melchior, D. E. W. Vaughan, C. F. Pictroski, J. Phys. Chem. 1995, 99, 6128-6144.

[41] F. Roozeboom, H. E. Robson, S. S. Chan, Zeolites, 1983, 3, 321-328.

[42] C. L. Angell, J. Phys. Chem. 1973, 77, 222-227.

[43] C. Brémard, M. Le Maire, J. Phys. Chem. 1993, 97, 9695-9702.

[44] Z. Qin, S. Zeng, G. Melinte, T. Bučko, M Badawi, Y. Shen, J.-P. Gilson, O. Ersen, Y. Wei, Z. Liu, X.

Liu, Z. Yan, S. Xu, V. Valtchev, S. Mintova Advanced Science, 2021, 10.1002/advs.202100001. 
